DOI 10.37882/2500-3682.2021.12.27

\title{
ПОШЛОСТЬ КАК ЯВЛЕНИЕ В СФЕРЕ ОБРАЗОВАНИЯ И КУЛЬТУРЫ
}

\section{VULGARITY AS A PHENOMENON IN THE FIELD OF EDUCATION AND CULTURE}

A. Frolov

Summary: The article discusses the phenomenon of vulgarity. The definition of the concept corresponding to this phenomenon is given and the features of its manifestation in modern education and culture are analyzed. The article substantiates the position that due to the radical changes taking place in modern capitalism, there is a danger of global and irreversible vulgarization of education and culture. The idea is expressed about the basic condition of opposing the process of vulgarization of education and culture.

Keywords: education, culture, vulgarity, identity, authenticity.

\author{
Фролов Анатолий Серафимович \\ Д.ф.н., профессор, Алтайский государственный \\ педагогический университет, г. Барнаул \\ asfrolof@mail.ru
}

Аннотация: В статье рассматривается феномен пошлости. Даётся определение понятия, соответствующего данному феномену, и анализируются особенности его проявления в современном образовании и культуре. 0босновывается положение о том, что в связи с происходящими в современном капитализме радикальными изменениями существует опасность глобальной и необратимой вульгаризации образования и культуры. Высказывается мысль об основном условии противостояния процессу вульгаризации образования и культуры.

Ключевые слова: образование, культура, пошлость, идентичность, подлинность.

Им, вроде, немного надо: Была бы прочна палатка, Да был бы нескучен путь...». Такой же чуждой данным социально-экономическим условиям является и установка системы образования на всестороннее, целостное развитие личности.

В полном соответствии с этим законом общественной детерминации культуры и образования указанный тип капитализма, характеризующий социально-экономическую основу современного российского общества, определяет тотальность и абсолютное господство «эстетики безобразного» и пошлости в культуре, а в образовании ориентацию на фрагментарное, усечённое, клиповое сознание и сиюминутный, вульгарно интерпретируемый прагматизм.

Пошлость и её синоним - вульгарность (от английского - vulgarity) являются понятиями, которые, на первый взгляд, выступают едва ли не антиподами образованности и образования. Однако более глубокий взгляд на образование приводит к иному выводу. Но для такого взгляда требуется и более глубокая, метафизическая оценка феномена пошлости.

Если обращаться к наиболее распространенному толкованию пошлости, то совершенно очевидным является то, что содержание соответствующего данному феномену понятия не только в современном языке повседневности, но часто и в научном дискурсе основывается на методе неполной индукции и ограничивается бытовой сферой. Это содержание сводится к приземлённости идеалов и базовых ценностей, неполноценной социализации личности, отсутствию хороших манер и умения вести себя в обществе, различным формам нарушения идентичности практического и речевого поведения и 
т.п. Вместе с тем, обращение к классической российской литературной и философской традиции приводит к более глубокому пониманию этого феномена и дает возможность сформулировать такое определение пошлости, которое позволяет обнаружить её в том или ином виде практически во всех сферах общественной жизни, включая образование и культуру.

Обратившись к первому русскому автору, для которого пошлость явилась самостоятельным и фактически основным предметом художественно-философского осмысления, - Н.В. Гоголю, мы обнаружим, что классик отечественной литературы понимал пошлость, в первую очередь, как «приземленность», «ничтожность», «скуку» и «бездуховность» в человеческом существовании; как ограничение человеческого бытия узким горизонтом земного, телесного. Как утверждает О.С. Рудова, говоря о творчестве Н.В. Гоголя, «В понимании классика пошлость - это, прежде всего, бездуховность, грубая телесность существования мира и обывателя в нём» [1, с. 134].

Аналогичное понимание феномена пошлости разделял один из наиболее глубоких аналитиков творчества Н.В. Гоголя, - В. Набоков, который вместе с тем расширил объем этого понятия, вынеся его за узкие рамки «ничтожного» существования обывателя, «маленького человека». Поднявшись на уровень метафизических обобщений, в литературно-критических «Николай Гоголь», «Пошляки и пошлость» [2] В. Набоков сформулировал понимание пошлости как качественную деформацию человеческой сущности и природы вещей, которая принципиально искажает их подлинность, делая их ложными, фальшивыми.

Близкое такому пониманию было толкование этого феномена Н.А. Бердяевым, который писал: «Пошлость есть совершенная удовлетворённость, довольство и даже веселье от плоскости небытия, окончательное выбрасывание на поверхность, окончательный отрыв от всякой глубины, от ядра бытия, боязнь всякого возвращение к глубине» [3, с. 158].Эта линия в определении феномена пошлости была продолжена в наиболее аргументированных и убедительных публикациях современных российских авторов (В.И. Толстых, И.Б. Левонтина, В.В. Глебкин, В.П. Козырьков и др.) $[4,5,6,7]$.

Обобщая этот опыт осмысления феномена пошлости, можно предложить следующее его определение: Пошлость есть сознательное, преднамеренное искажение, частичная или полная утрата своей идентичности (подлинности, тождественности) человеческой личностью, социальной группой, обществом, государством и деформация человеком идентичности предметного, вещного мира в отношениях к нему. Такое философское определение понятия пошлости даёт основание, сузив его содержание, в соответствии с законами логики прин- ципиально расширить его объём и онтологию, область бытования.

Рассматривая современную социальную реальность через призму данной дефиниции, мы уже в первом приближении, во-первых, - убедимся в том, что феномен пошлости не просто присутствует в этой реальности, а чаще всего господствует в ней. Поэтому далеко не случайно В.И. Толстых, говоря о пошлости как старой теме, отметил; «Старая тема светских разговоров ныне приобрела «вселенский» масштаб и остроту в связи с тотальностью самого процесса опошления социальной реальности» [3, с. 105]. Во-вторых, - обнаружим, что, подобно неразрывной связи различных сфер общественной жизни, тесно связаны и различные виды пошлости. Поэтому характеристика пошлости и ее причин в культуре и образовании была бы неубедительной, если это делать вне связи с пошлостью в области экономических, политических и правовых решений. Тем более, что основной причиной существования пошлости в культуре и образовании является деформация и утрата своей идентичности, подлинности экономикой и политикой. Причём, это относится к социальной реальности как России, так и зарубежных стран.

Обращаясь к российской реальности, мы без труда, но с полным основанием придем к выводу о том, что качественно деформировала свою идентичность (следовательно, стала неподлинной, опошлилась) экономика и в первую очередь, - реальная экономика, связанная со сферой материального производства. В отличие от материального производства современного Запада, переживающего перманентные технологические перестройки и модернизации, отечественный реальная экономика во многом деиндустриализировалась и принципиально усилила свой колониально-сырьевой характер. Качественно деградировали не только те области материального производства, которые определяют темпы экономического развития и конкурентноспособность страны на мировом рынке, но и лёгкая промышленность. Потребность в одежде и обуви значительной, если не абсолютно преобладающей части российского населения, удовлетворяет китайский производитель. И едва ли не основным «брендом» современной российской экономики стал печально знаменитый, виртуальный ё-мобиль. К такой, абсолютно не соответствующей современным задачам экономике страны, которая в недалёком прошлом значительное время лидировала в освоении космоса, принципиально не применимо понятие подлинности, идентичности.

Однако и экономика современного Запада утратила свою идентичность. Но здесь опошление этой базовой сферы имеет совершенно иное содержание. В соответствии с парадигмой постмодерна экономика стран Запада трансформировалась из механизма удовлетворения 
жизненных потребностей, - в чём и состоит сущность экономики в её классическом понимании, - в машину по удовлетворению искусственно формируемых желаний. Обозначая такой мутировавший, утративший идентичность тип экономики понятиями «трансэкономика», «вирусная экономика» [8, с. 115], современный французский философ Ж.Бодрийяр утверждает, что это - «...триумф экономики, освобожденной от экономических законов и предоставленной чистой спекуляции», что «экономика становится ареной современной жизни именно в качестве арены спецэффектов, непредсказуемых результатов иррациональной игры» [8, с. 115].

Подобное же утверждение неподлинного, поддельного произошло в политической жизни. Причем, это тоже относится не только к России, но ко всем развитым странам, в которых на смену классическому пришло общество, маркируемое западными философами понятием «общество постмодерна». Так, например, электоральный процесс основывается уже не на принципах репрезентативных отношений между избирателями и кандидатами (когда кандидат представляет объективные потребности и интересы избирателя), - как это вытекает из самой сущности, неискажённой подлинной, идентичной системы политического представительства, а на символическом «удовлетворении» этих потребностей с помощью действующего на подсознание избирателей «текста», - броского имиджа, громко и пламенно произнесённой предвыборной фразы, пафосного спича в Парламенте и т.п.

Политическое пространство современной России является объёмной «энциклопедией» крайне многообразных форм такого символического «удовлетворения» потребностей и интересов электората, или деформации идентичности, подлинности политики, то есть, политической пошлости. Как писал об этой трансформации политики в современном мире, включая Россию, проницательный философ и социолог А.С. Панарин, обращаясь к термину «текст» в его постмодернистской интерпретации, - «Отсюда понятие интертекстуальности - взаимной наложенности множества текстов, которые легитимируются не по критерию своей соотнесённости с реальностью, но по критерию соотнесённости с другими, «авторитетными» текстами» [7, с. 66]. Иными словами идентичность, подлинность политических отношений принципиально деформируется, заменяясь имитацией и игрой и превращается в пошлость.

Вполне комфортно пошлость себя чувствует и в законотворческой сфере, где продукты «творчества» слишком часто находятся в антагонизме со своим общественным назначением. Так, обратимся для примера к Федеральному закону от 2013/06/30, который в публицистической практике получил краткое название закона «о защите религиозных убеждений и чувств верующих». В этом правовом акте идентичность закона как правово- го нормативного акта искажается, как минимум, дважды: Во-первых, природа правовой нормы категорически исключает неопределённость понятий, в которых он формулируется. Но о какой определённости в данном случае можно говорить, если в научной литературе до сих пор отсутствует чёткое и общепринятое определение понятия «религиозного чувства»...

Во-вторых, - идентичность, тождественность закона самому себе предполагает в качестве обязательного условия равенство перед ним всех граждан. Именно на этот принцип указывает римское «Dura lex, sed lex» - «3aкон суров, но это закон». Односторонняя декларация правовой защиты «религиозного чувства» верующих без аналогичной правовой гарантии для «атеистического чувства» неверующих в светском, нетеократическом государстве, которым, согласно Основному Закону страны, пока ещё является Россия, есть также грубое искажение идентичности закона как правовой нормы.

Изложенное выше делает вполне объяснимым, что в культуре (в широком смысле), отношения которой с политикой и правом в современной России выстраиваются по принципу жёсткой субординации, пошлость не просто доминирует, она часто торжествует. Именно культура, которая по своей природе и сущности является возделыванием человеческого ума и души (римское cultura означает возделывание, улучшение), более всех других сфер общественной жизни деформировала свою идентичность, подлинность, тождественность трансформировавшись в нечто постыдное и непристойное. Это же, но только значительно раньше, произошло и в странах «цивилизованного» Запада.

Русский философ В.С. Соловьев сформулировал собственное понимание морали, основой которой, по его мнению, должны быть чувство стыда, чувство жалости (сострадания) и чувство благоговения и которая должна быть фундаментом подлинной культуры [ 8, с. 51-52]. Утративший свою идентичность, подлинность и абсолютно господствующий в современном обществе тип «культуры» даже «не догадывается» об этих чувствах. Семантически ёмкий и ценный для теоретических обобщений фактический материал, связанный с тотальным опошлением отечественной культуры в постсоветской России содержится в книге известного отечественного реставратора и общественного деятеля, всеми своими силами защищавшего подлинную культуру, С.В. Ямщикова [9].

Трагично то, что к такому типу «культуры» в современной России человек начинает приобщаться с младенчества. Здесь, к какому бы виду детской культуры мы не обратились, практически везде торжествует «эстетика безобразного», которая уже в самом раннем возрасте блокирует возможность формирования у детей базовых нравственных ценностей, о которых писал В.С. Соло- 
вьев и которые являются духовной основой созидательно-конструктивной и целостной личности. Достаточно в этой связи обратиться к такому наиболее массовому виду современной детской культуры, которая охватывает самое раннее детство, начиная с однолетнего возраста, - к культуре детской раскраски. Нельзя переоценить нравственную и духовную функции этого вида детской культуры. Но у нравственно позитивно сформированного взрослого человека, который начинает приобщать своих детей и внуков к этой культуре на практике, при первом посещении с этой целью книжного магазина возникает шок: среди сотен маленьких и больших, тонких и толстых книжек-раскрасок, которыми заполнены полки современного книжного магазина, абсолютно преобладают раскраски, созданные в формате «эстетики безобразного»!!!

Белоснежки и зайчики, котята и утята практически полностью вытеснены образами агрессивных уродцев, монстров, киборгов, приведений и прочей инфернальной нечисти! Едва ли не самыми «человечными» здесь являются образы роботов и различных машин и механических устройств! Если иметь в виду исключительную образовательно-воспитательную роль данного вида детской культуры в раннем детстве, то становится понятной прямая корреляция между торжеством в ней агрессивной пошлости и ростом детской и подростковой «немотивированной» жестокости, агрессивности и преступности. А трагическим аргументом, иллюстрирующим эту связь на практике, являются резко участившиеся случаи расстрелов учащихся в российских школах, колледжах и вузах.

Если обращаться к специфике феномена пошлости в сфере образования, то нельзя не заметить, что еще в 1974 году в отечественной литературе появился термин, которым А.И. Солженицын обозначил тип образования с утраченной идентичностью, подлинностью. Таким термином является «образованщина». Этим термином писатель обозначал образование, в котором сочетаются поверхностностные знания, ложные духовные и нравственные установки, ориентация на получение вузовского диплома как основную цель и «духовное высокомерие» [10]. И хотя использование термина «образованщина» не стало устойчивой традицией в отечественной научной и публицистической литературе, связанное с его происхождением эссе А. И. Солженицына сыграло свою конструктивную роль в осмыслении и системном научном анализе глубинных, базовых причин искажения идентичности, подлинности культуры и образования.

Исследование конкретного эмпирического материала, связанного с развитием в течение последних трёх десятилетий отечественного образования, позволяет сделать вывод, что из многообразных типов пошлости, доминирующих в системе современного образования (прежде всего высшего) и приведших к наибольшим деструктивным последствиям, особенно выделяются два тесно взаимосвязанных типа. Один из них основан на принципе сознательного упрощения сложного, к чему сводится буквальное значение термина «вульгаризация». В основе другого лежит формально противоположный принцип преднамеренного усложнения простого.

Обращаясь к первому из выделенных типов искажения идентичности образования, мы обнаруживаем, что в современной России утвердилась крайне упрощенная образовательная стратегия, которая заключается в жёсткой привязанности системы образования к потребностям предельно деформированной, колониальносырьевой экономики и связанного с этой экономикой «номенклатурно-родового» капитализма, породившего соответствующий, - «дикий» рынок. Сущность этого рынка заключается в том, что крупный капитал задействует ресурсы политической власти для освобождения экономического пространства от своих реальных и потенциальных конкурентов.

Социальный заказ господствующего класса системе образования в таком контексте определяется жёсткой привязанностью к императиву сиюминутной прибыли, тупой ориентацией на конъюнктуру. В такой ситуации авторов заказа на подготовку специалистов абсолютно не интересует долгосрочная экономическая перспектива, требующая больших инвестиций, и принципиально меняющих номенклатуру специальностей формируемых системой образования кадров высшей квалификации. Для превратившейся в «сферу услуг» системы высшего образования заказ на подготовку специалистов для крупного капитала, процветающего без конкуренции, носит императивный характер. Так неподлинная, утратившая идентичность, опошленная экономика современной России искажает идентичность, опошляет всю систему образования и прежде всего высшего, лишая его должной динамики, ориентации на перспективу конструктивного, органичного и целостного развития общества.

Одной из вызывающих наибольшую тревогу у научно-педагогического сообщества страны опасностей радикальной вульгаризации высшего образования является резкая, катализируемая ковидной эпидемией активизация адептов перевода системы образования, включая высшее, в дистанционный формат. Причем, этот формат позиционируется не как временный и обусловленный форс-мажорными обстоятельствами, а в качестве нормы, открывающей неограниченные возможности и творческие перспективы.

Обращает на себя тот факт, что в последнее время различные представители российского топменеджмен- 
та, политической элиты активно прессингуют общественное мнение, рекламируя дистанционную форму обучения в качестве прогрессивной и имеющей несомненные преимущества перед классической формой образования. Можно вполне согласиться с такой пафосной, эмоционально возвышенной рекламой, но только при одном обязательном условии: если адепты «дистанционки», проведя множество экспериментов, безусловно, используя себя и своих сторонников в качестве материала, убедительно докажут, что дистанционный, «бесконтактный» обед гораздо прогрессивнее и полезнее, чем обед в традиционной, «контактной», то есть нормальной, естественной форме!

Уместно заметить, что идея дистанционного обучения как массовой модели для «плебса» имманентна той модели нового глобального общественного устройства, которую сегодня активно навязывают миру её пассионарные идеологи, проектировщики и технологи в интересах «глобального бизнеса» и в формате концепции «золотого миллиарда». Возможность утверждения такого «мирового порядка» и адекватного ему «трансгуманистического» общества предполагалась и жила в интеллектуальных интуициях западных и отечественных ученых и литераторов еще в прошлом веке. Так, например, Жак Эллюль вопреки преобладавшим при его жизни оптимистическому пафосу и демократическим настроениям утверждал, что в будущем человек будет жить «(...) в тоталитарном государстве, которым правит гестапо в бархатных перчатках» [11, с. 288].

Идея создания с помощью ставших реальностью био-, инфо- и медицинских технологий касты «служебных людей», обслуживающих касту «господ» - идея, перекочевавшая из романов-антиутопий недавнего прошлого в проекты глобального общественного переустройства, по мнению ряда отечественных социальных философов и политологов, предполагает и радикальное упрощение, вульгаризацию сформировавшейся за многие века сложной системы образования западных стран. Серьёзным катализатором активного обсуждение этой проблемы в России является по различным каналам доходящая до российского научно-педагогического сообщества информация о пока лишь фрагментами переведённой на русский язык книге профессора Гарвардского университета Шошаны Зубофф «Эпоха надзирающего капитализма» [12]. Из этой книги следует такой же вывод о качественной вульгаризации, опошлении системы образования в случае утверждения данной модели капитализма. Если учитывать предельно вульгаризированную социальную философию и философскую антропологию, лежащие в основе данной модели, то есть все основания утверждать, что глобальная вульгаризация образования и культуры не приведёт «золотой миллиард» к «золотому веку» и гарантированно вечной земной «нирване», а неизбежно обернётся для челове- ческого рода всеобщей катастрофой.

Упрощение сложного как тип искажения подлинности образовательного процесса в российском контексте выражается также в свертывании образования до обучения и фактическом отказе от воспитания, что оборачивается формированием ограниченной, односторонней, «усечённой» личности, нечувствительной к нравственным и духовным ценностям, - личности, для которой на порядок затрудняется процесс социализации, адаптации к динамично меняющейся социальной реальности, а также становится проблематичным участие в подлинной межличностной и межкультурной коммуникации.

Другой тип нарушения подлинности, идентичности российского образования, особенно высшего, заключается в искусственном усложнении простого. Прежде всего, он выражается в прочно утвердившемся приоритете форм, методик, технологий над содержанием. Непрерывное мельтешение различных инструкций, постоянный самоценный пересмотр образовательных стандартов, доходящее до абсурда отсутствие разумной стабильности в перечне компетенций и их соотнесённости с определёнными дисциплинами, когда даже по близким направлениям подготовки в одних и тех же дисциплинах указываются совершенно различные компетенции, - это и многое-многое другое создаёт путаницу, искусственно усложняет образовательный процесс, уводя в сторону от его содержания.

Лихорадочное утверждение инноваций, - болезнь, получившая название «неопатии», о зарождении которой писал ещё Ф.М. Достоевский, сегодня поразила образовательный процесс, особенно его высшую ступень, подобно ковидной эпидемии, искажая его подлинность, идентичность и заслоняя главное, - содержание, которое, как правило, можно оптимально транслировать обучающимся на порядок более простыми способами, методами и технологиями.

Подлинные, истинные образование и культура в современном мире являются необходимыми условиями обеспечения идентичности человека как социального и духовного существа, как личности. Минимизация неподлинного, ложного, пошлого в культуре и образования позволяет человеку находить оптимальные пути реализации как своей родовой сущности, так и индивидуальности, личностной уникальности, неповторимости.

Но всё это требует одного фундаментального и обязательного условия: Бытие человека как существа сверхбиологического не должно находиться в жёстком формате сугубо физического выживания, - что, как это ни парадоксально, имеет место для значительной части населения современной России с её громадными природными и духовно-интеллектуальными ресурсами. 
Поэтому обеспечение подлинности образования и культуры предполагает принципиальную смену социальноэкономического курса, его переориентацию с вектора, качественно усиливающего и без того «зашкаливающие» социальные контрасты и пропасти, разделяющие уров- ни материального благополучия различных социальных групп, на вектор противоположный, способный обеспечить восстановление подлинной, идентичной экономики и политики России как единой, целостной и процветающей страны.

\section{ЛИТЕРАТУРА}

1. Рудова 0.С. Проблема пошлости: Взгляды Н.В. Гоголя и В.В. Набокова // Международный журнал социальных и гуманитарных наук. 2016. Т. 4. №1. C. 134-138.

2. Бердяев Н.А. 0 назначении человека. М.: Книжный клуб; Республика, 1998. - 382 с.

3. Набоков В.В. Лекции по русской литературе. М.: Независимая газета, 1981. - С. 20-130.

4. Толстых В.И. Пошлость как нашествие // Свободная мысль. 2009. № 4. - С. 103-112.

5. Левонтина Б.И. «Осторожно, пошлость!» [электронный ресурс] Режим доступа: URL: http://ec-dejavu.ru/t/Triteness_a/html (дата 0бращения - 25.10.2021)

6. Глебкин В.В. Пошлость [электронный ресурс] Режим доступа: URL: http://otimk.ru/files/Poshlost'doc (дата обращения - 25.10.2021)

7. Козырьков В.П. Социокультурные аспекты пустоты //Вестник Нижегородского университета им. Н.И. Лобочевского. Серия Социальные науки. 2021. № 1 [25] - C. 57-64.

8. Панарин А.С. Народ без элиты. М.: АЛГОРИТМ, 2006. - 352 с.

9. Соловьёв В.С. Оправдание добра. Нравственная философия // Сочинения в 2 т. Т. 1. - М.: Мысль, 1988. - 892 с.

10. Ямщиков С.В. Антикультурная революция в России. М.: Алгоритм, 214. - 224 с.

11. Солженицын А.И. Образованщина // Новый мир. 1991. № 5. - С. 28-46.

12. Цит. По: Тоффлер Э. Шок будущего: Пер. с англ. / Э. Тоффлер. 000 «Издательство АСТ», 2001. - 560 с.

13. Эпоха надзирающего капитализма. Борьба за будущее человечества на грани реальности. (Перевод Сергея Катукова из книги Шошаны Зубофф) [электронный ресурс ] - Режим доступа: URL: https://litbook.ru/article/14498/ (дата обращения - 27.10.2021)

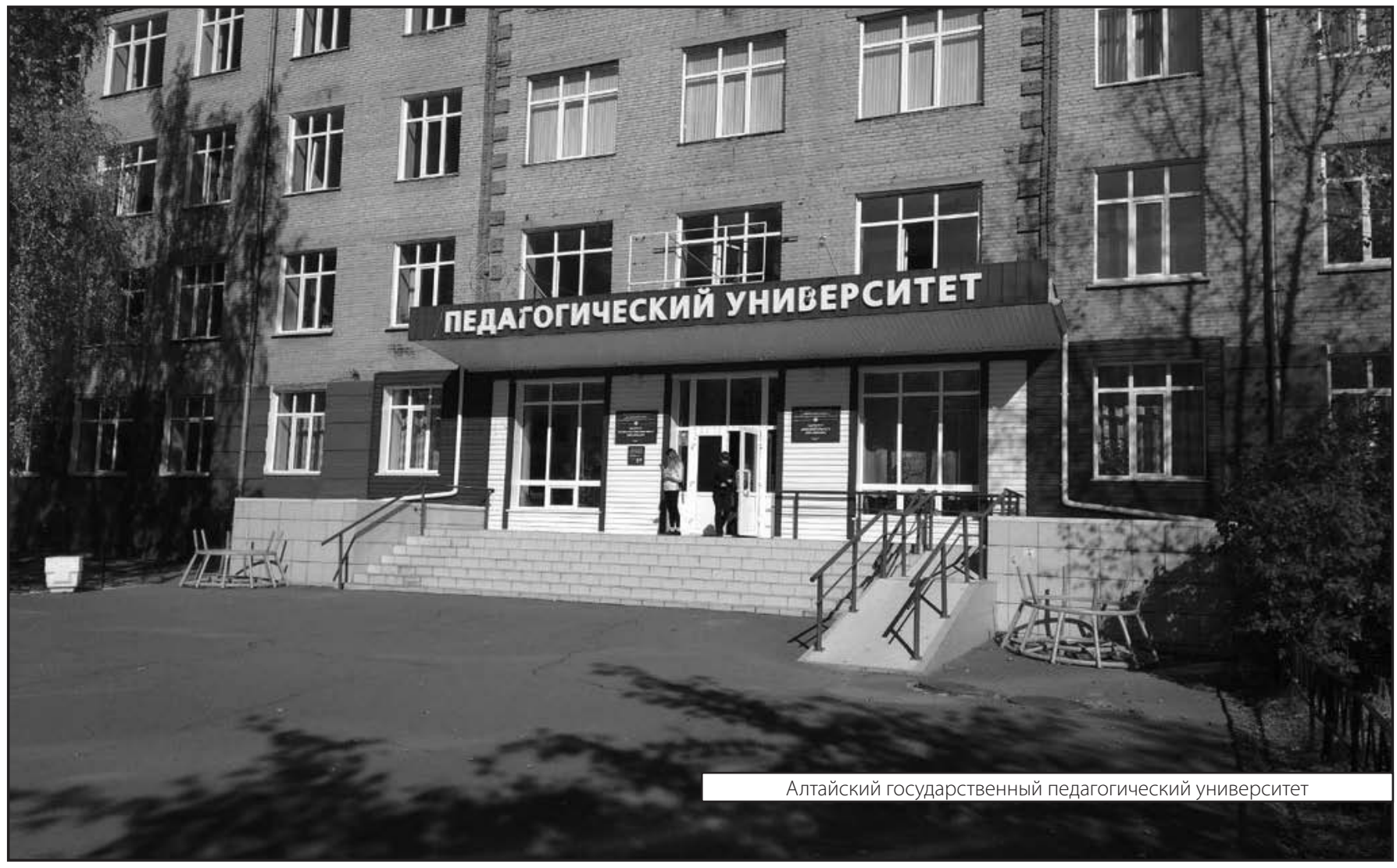

